\title{
Chemically Enhanced Solid-Liquid Separation of Digestate: Suspended Solids Removal and Effects on Environmental Quality of Separated Fractions
}

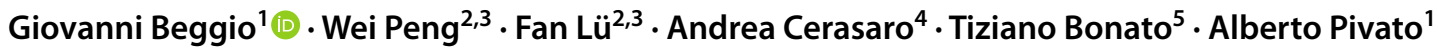

Received: 5 May 2021 / Accepted: 20 September 2021 / Published online: 5 October 2021

(C) The Author(s) 2021

\begin{abstract}
Chemically enhanced solid-liquid separation (CES) of digestate can improve its membrane filterability but potentially influence the environmental features of the separated solid fraction, thus hindering its possible agricultural reuse. In this study, the effects were assessed of different dosages of polyaluminum chloride (PAC), epichlorohydrine-dimethylamine with ethylendiamine (DEED) and polyacrilamides (PAM) on CES of digestate from biowaste in terms of Total Suspended Solid (TSS) mitigation in the liquid fractions and resulting environmental quality of the solid fractions. Results from labscale trials showed that applied chemicals significantly increased the centrifugation efficiency with achieving minimum TSS concentration of $2347 \pm 281 \mathrm{mgTSS} / \mathrm{L}$ (up to $90 \%$ improved TSS mitigation). Also, performed treatments led to almost complete removal of $\mathrm{P}$ and Heavy Metals (HMs) from the liquid fractions after centrifugation. Conditioned solid fractions showed higher $\mathrm{Al}$ (reaching $20 \mathrm{~g} \mathrm{~kg}^{-1} \mathrm{TS}$ ), organic carbon and nitrogen content (up to $324 \mathrm{mgTOC} \mathrm{kg}^{-1} \mathrm{TS}$ and $44.1 \mathrm{mgTKN}$ $\mathrm{kg}^{-1}$ TS, respectively) due to residual PAC, DEED and PAM. However, achieved concentrations of HMs guaranteed full consistency with EU regulation limits established for agricultural reuse of organic soil amendments. Further, leaching tests performed on the treated solid fractions indicate higher chlorides and soluble $\mathrm{Al}$ concentrations in the water extracts (up to $4.6 \mathrm{~g} \mathrm{~L}^{-1}$ and $2.3 \mathrm{~g} \mathrm{~L}^{-1}$, respectively), but lower HMs leachability from the digestates undergone CES. Nevertheless, water extracts from treated biosolids were characterized by higher phytotoxicity, likely related with direct Al toxicity and increased salinity due to chemicals addition. Accordingly, the effects on soil-plant system should be better investigated when agricultural reuse of CES-treated solid fraction of digestate is foreseen.
\end{abstract}

\section{Graphic abstract}

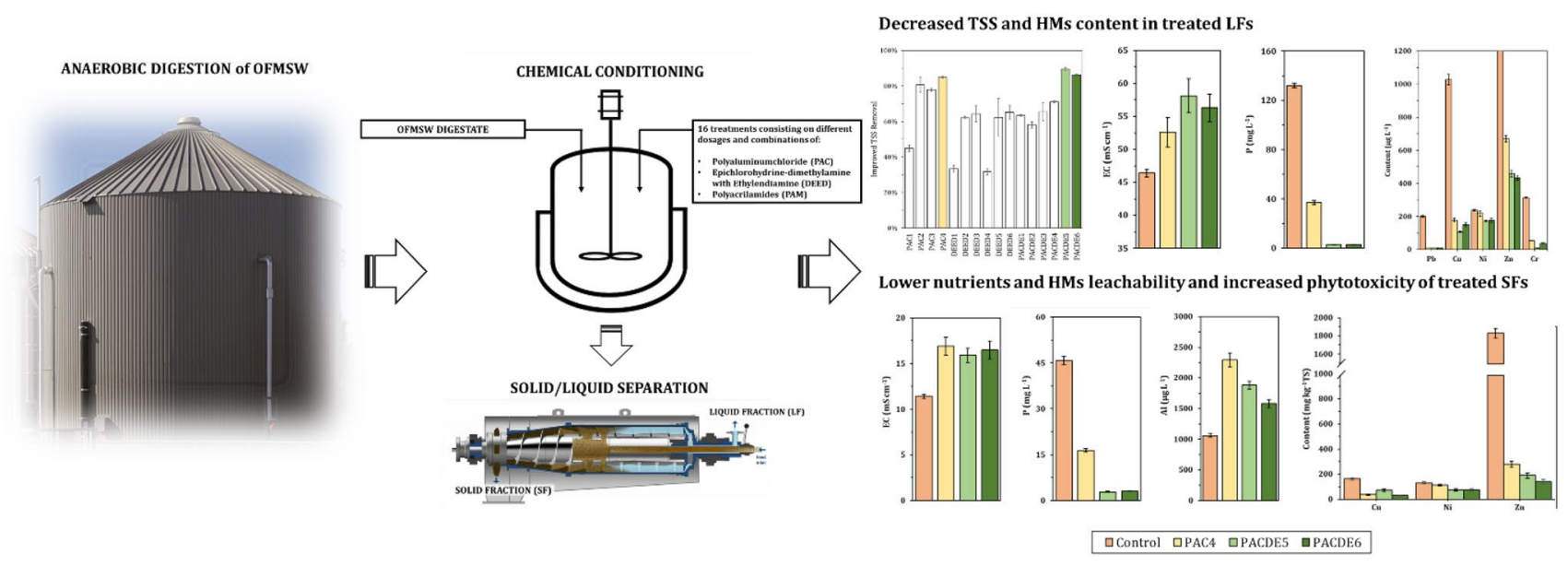

Keywords Dewatering $\cdot$ Biogas effluent $\cdot$ Coagulation $\cdot$ Flocculation $\cdot$ Biowaste $\cdot$ Phytotoxicity $\cdot$ Agricultural reuse

Extended author information available on the last page of the article 


\section{Statement of Novelty}

The relevance of the paper lies on: from a circular economy perspective, the results allow to understand whether the application of CES can help to achieve the requirements established by the planned valorization/disposal scenario of the resulting digestate fractions.

The authors think that it represents a novel contribution since: it assesses effects of CES application on digestate from the $\mathrm{AD}$ of biowaste, where relevant papers in the literature were focused on digestate from animal manures and agro-industrial residues; it addresses the issue of final environmental quality of conditioned digestate fractions intended for agricultural reuse, which is currently scarcely reported in previous literature.

The paper will be beneficial to related academic research and practical application concerned with digestate separation and management of separated fractions.

\section{Introduction}

The EU-28 yearly production of digestate was estimated in almost 180 million tons, derived from the Anaerobic Digestion (AD) of both the source separated biowaste and the agro-industrial residues [1]. In this context, digestate quality management, achieved through the application of specific treatment technologies, can determine its possible market valorization as organic fertilizer, while avoiding additional costs due to further treatment or disposal as a waste $[2,3]$. In recent years, AD digested residues are also gaining increasing attention as key substrates to produce several high-value biobased products from biorefinery 2.0 processes $[4,5]$.

Digestate processing technologies consist primarily of solid-liquid separation, performed to achieve i) reduced volumes, thus improving handling and decreasing transportation and storage costs, and ii) substances fractionation in concentrated solid and liquid fractions together with the complete purification of the remaining liquid fraction $[4,6,7]$. This latter could be reused in situ according to the concept of zero water discharge when applied on AD plant design.

The concentration of digestate valuable components and the complete purification of the liquid fraction can be effectively achieved through the application of the whole range of membrane technologies, from microfiltration to reverse osmosis $[8,9]$. However, when applied on digestate, membrane processes should include mandatory pretreatment aimed at decreasing the specific high concentration of total suspended solids (TSS), which is the main cause of membrane fouling, decreased separation efficiency and short membrane service life [10-12]. Chemically enhanced solid-liquid separation (CES), consisting of the dosage of a combination of chemical products (mostly polyelectrolytes and organic polymers) followed by solid-liquid separation step (e.g. centrifugation, screw press, etc.), has been implemented to solve this issue and proved to outperform regarding low cost and simple operations $[13,14]$. Chemical conditioning improves the efficiency of the following solid-liquid separation by achieving particles coagulation, i.e., destabilization/neutralization of particles charged surface, and further aggregation of destabilized particles (i.e., patch flocculation and polymers bridging) [15]. The relative influence of the three mechanisms depends on the specific chemical-physical features of the substrate to be treated, e.g., electroconductivity, specific concentration of suspended particles (TSS) and charge distribution of the suspended particulate matter. For this reason, and as reported by Hjorth and Jørgensen, (2012) for manures, the optimal combination between the type of suitable chemicals and their dosage can vary widely between different typologies of digested residues, as derived from a multitude of input feedstocks and the different set of $\mathrm{AD}$ technologies. In the wastewater treatment sector, Polyaluminum chloride (PAC), polyacrylamide (PAM) and epichlorohydrine-dimethylamine with Ethylendiamine (DEED) are among the most efficient coagulant and flocculant products used for sludge dewatering [17]. Some authors demonstrated the efficacy of PAC and cationic PAM, under very different dosage configurations, on digested residues from $\mathrm{AD}$ of pig slurries and other agro-industrial substrates [11, 18, 19]. Further, Borowski et al. [20] assessed the effects of several CES products on digestates from a pilot-scale co-digestion of lab-reconstructed food waste, slaughterhouse waste and municipal sewage sludge. Indeed, AD plant configuration and substrate-specific features are crucial factors influencing the efficiency of applied solid-liquid separation technologies, both in terms of TSS mitigation and final composition of the separated fractions [21]. Here, food waste digestates has already shown lower dewaterability if compared with manure and sewage sludge digestates [22]. To the best of our knowledge, no previously published study investigated the efficiency of CES when applied on digestates derived from a full-scale biogas plant treating separately collected biowaste.

The potential use of the separated solid fraction of digestate as a substitute for mineral and fossil-based amendment/ fertilizers has been largely supported by the scientific literature [23-26]. Consequently, they were recently included within the updated regulation on CE-marked fertilizers as potential "Component Material Category" [27]. This regulation establishes requirements on process specifications and 
chemical-physical and biological parameters, which can be considered "End-of-waste" criteria for those substrates derived from the $\mathrm{AD}$ of biowaste. Consequently, the nonconformity with these limits can determine their further treatment (e.g., thermal) or disposal as wastes [7]. In this context, CES application could arise doubts regarding the compliance of treated biosolids with legal requirements established for agricultural reuse. Also, non-regulated chemical-physical properties and environmental behavior of treated solids (e.g., possible increased phytotoxicity due to residual byproducts of used chemicals) must be assessed to support scientifically sound decisions on sustainable agricultural reuse or safe disposal of fractions from CES. In this context, the integrated approach between leaching test and phytotoxicity testing was efficiently used to understand the overall environmental quality of treated digested residues [28, 29].

To address these gaps, lab-scale CES trials involving PAC, DEED and PAM in various dosages were performed on digestate derived from a full-scale AD plant located in Northern Italy. The choice of conditioning products was based on the experience of the manufacturing company in the wastewater sector and the consequent possibility of market expansion in the field of biogas plants treating biowaste. Results allowed to assess (i) CES efficiency in terms of suspended solids mitigation in the separated liquid fraction and (ii) the influence of used chemicals on the overall environmental quality of treated solid fraction with a view to possible agricultural reuse.

\section{Materials and Methods}

\section{Materials}

About $50 \mathrm{~L}$ of raw digestate was sampled once at the output of 4 anaerobic digesters, operated in parallel in wet thermophilic conditions (TS $10 \%, 55^{\circ} \mathrm{C}$ ) with a hydraulic retention time of 21 days and treating yearly about 120,000 tons of biowaste, separately collected from several municipalities located in Veneto region in North-East Italy. Sampled digestate was stored in polyethylene (PE) containers at $4{ }^{\circ} \mathrm{C}$ for no more than 3 weeks. Physicochemical features of the sampled digestate are listed in Table 1.

Three coagulant products were tested: polyaluminum chloride (PAC), Epichlorohydrine-dimethylamine with Ethylendiamine (DEED), a mixture of $30 \%(\mathrm{w} / \mathrm{w})$ PAC with 70\% (w/w) DE (PACDE). Further, 2 flocculants, a cationic and an anionic polyacrylamide characterized by high molecular weight (CPAM, APAM), were investigated. The investigated products are commercially available to the wastewater treatment plant sector (i.e., currently not sold for digestate treatment). Manufacturing process and the exact
Table 1 Physicochemical characterization of whole digestate (i.e., unseparated) used for lab-scale CES experiments

\begin{tabular}{lll}
\hline Parameter & Unit & Value \\
\hline $\mathrm{pH}$ & - & $8.2 \pm 0.7$ \\
$\mathrm{EC}$ & $\mathrm{mS} \mathrm{cm}$ & $46.9 \pm 4.7$ \\
$\mathrm{TS}$ & $\mathrm{g} \mathrm{kg}^{-1} \mathrm{FM}$ & $103 \pm 9$ \\
$\mathrm{VS}$ & $\mathrm{g} \mathrm{kg}^{-1} \mathrm{TS}$ & $523 \pm 37$ \\
$\mathrm{TKN}$ & $\mathrm{g} \mathrm{kg}^{-1} \mathrm{TS}$ & $83.3 \pm 2.4$ \\
$\mathrm{TAN}$ & $\mathrm{g} \mathrm{kg}^{-1} \mathrm{TS}$ & $69.3 \pm 3.2$ \\
$\mathrm{P}$ & $\mathrm{g} \mathrm{kg}^{-1} \mathrm{TS}$ & $10.7+0.4$ \\
$\mathrm{Cd}$ & $\mathrm{mg} \mathrm{kg}^{-1} \mathrm{TS}$ & $0.43+0.04$ \\
$\mathrm{~Pb}$ & $\mathrm{mg} \mathrm{kg}^{-1} \mathrm{TS}$ & $15.37+1.33$ \\
$\mathrm{Cu}$ & $\mathrm{mg} \mathrm{kg}^{-1} \mathrm{TS}$ & $57.55 \pm 11.06$ \\
$\mathrm{Hg}$ & $\mathrm{mg} \mathrm{kg}^{-1} \mathrm{TS}$ & $0.07 \pm 0.01$ \\
$\mathrm{Ni}$ & $\mathrm{mg} \mathrm{kg}^{-1} \mathrm{TS}$ & $5.84 \pm 0.14$ \\
$\mathrm{Zn}$ & $\mathrm{mg} \mathrm{kg}^{-1} \mathrm{TS}$ & $168.00 \pm 5.75$ \\
$\mathrm{Cr}$ & $\mathrm{mg} \mathrm{kg}^{-1} \mathrm{TS}$ & $10.75+1.66$ \\
\hline
\end{tabular}

Data are reported as mean \pm standard deviation $(n=3)$. All data are expressed as mean and standard deviation $(n=3)$ and on a dry basis (TS), except $\mathrm{pH}, \mathrm{EC}$ and $\mathrm{TS}(\mathrm{FM}=$ fresh matter)

products composition cannot be reported since they are patented information.

\section{Experimental Setup}

The experimental activity was conducted stepwise. A preliminary phase was first performed to assess the effective range of dosages of the chosen chemical products on the digestate. Dosages were selected based on the outcomes from visual examination of rate of coagulation and flock settling velocity occurring after chemicals addition on digestate samples. First, the dosages were applied according to the existing know-how of the manufacturer, which is based on the application of CES on urban and industrial wastewater treatment, and not on digestate processing. Based on the results achieved from the preliminary phase, 16 effective treatments were tested in the final definitive phase, resulting from the mixed dosage of the 3 coagulants (PAC, PACDE, DEED) and 2 flocculants (CPAM and APAM). Also, one control treatment involved no chemicals addition. The tested treatments (products and dosages) applied on the definitive phase are resumed in Table 2.

\section{Lab-Scale CES Performance}

During both preliminary and definitive phases, lab-scale CES experiments were carried out based on Borowski et al. [20] with some modifications. Accordingly, CES trials were performed by use of Jar Test apparatus equipped with impellers. For each performed treatment, a volume of $1 \mathrm{~L}$ of whole (i.e., unseparated) digestate was poured into 
Table 2 Treatments and relative dosages of conditioning products investigated in the definitive phase of the lab-scale CES experiments

\begin{tabular}{llllll}
\hline Treatment & PAC g L & DEED g L & PAC + DE g L $^{-1}$ & APAM mg L $^{-1}$ & CPAM mg L $^{-1}$ \\
\hline Control & - & - & - & - & - \\
PAC1 & 1.8 & - & - & 0.2 & - \\
PAC2 & 1.8 & - & - & - & 0.2 \\
PAC3 & 3.6 & - & - & 0.2 & - \\
PAC4 & 3.6 & - & - & - & 0.2 \\
DEED1 & - & 0.1 & - & 0.2 & - \\
DEED2 & - & 0.1 & - & - & 0.2 \\
DEED3 & - & 0.2 & - & 0.2 & - \\
DEED4 & - & 0.2 & - & - & 0.2 \\
DEED5 & - & 0.6 & - & 0.32 & - \\
DEED6 & - & 0.6 & - & - & 0.32 \\
PACDE1 & - & - & $0.54+0.7$ & 0.2 & - \\
PACDE2 & - & - & $0.54+0.7$ & - & 0.2 \\
PACDE3 & - & - & $1.00+1.4$ & 0.2 & - \\
PACDE4 & - & - & $1.00+1.4$ & - & 0.2 \\
PACDE5 & - & - & $3.2+4.2$ & 0.32 & - \\
PACDE6 & - & - & $3.2+4.2$ & - & 0.32 \\
\hline
\end{tabular}

Dosages are expressed in mass ( $\mathrm{g}$ ) of compound per unit volume $(\mathrm{L})$ of whole unseparated digestate a $2 \mathrm{~L}$ glass container, upon shaking and mixing it within the $50 \mathrm{~L}$ PE container, to avoid eventually occurred sedimentation during storage.

Whole digestate was initially stirred for $10 \mathrm{~s}$ at $300 \mathrm{rpm}$ to allow homogenization. While being continuously stirred, chemicals were spiked according to the chosen dosages: PAC and PACDE were added directly to the digestate, while DEED and polyacrylamides (APAM and CPAM) were first dissolved in distilled water to $10 \%$ and $0.2 \%$ (vol/vol) concentrations, respectively. Afterwards, conditioned digestate was stirred for other $60 \mathrm{~s}$ at $300 \mathrm{rpm}$, followed by slow stirring for $600 \mathrm{~s}$ at $50 \mathrm{rpm}$. Only for the definitive phase, each replicate test sample (i.e., $1 \mathrm{~L}$ subdivided in $4 \times 250 \mathrm{~mL}$ centrifugation vessels) was finally centrifuged (MPW 352, Poland) at $4000 \mathrm{rpm}$, ca. 3.000 relative centrifugal force $(\mathrm{RCF})$, for $10 \mathrm{~min}$ at room temperature (ca. $20^{\circ} \mathrm{C}$ ).. Here, bench-scale centrifugation was used as a simplified model of a decanter centrifuge. In particular, the values used for RCF and related rpm were chosen to simulate typical values of full-scale centrifugation applied to digestates [30-32]. Also, a residence time of $600 \mathrm{~s}$, as used in this work, proved to be efficient for dry matter and phosphorous separation in lab-scale centrifugation of pig and cattle manure [14].

After centrifugation, the liquid fractions were carefully collected by suction through $100 \mathrm{~mL}$ plastic syringes and the solid fractions were removed from the bottom of the centrifugation vessels by small palette knives.Each treatment (Table 2) was tested in triplicate by repeating the full lab-scale CES procedure (i.e., chemical conditioning + centrifugation).

\section{Analyses}

\section{Physicochemical Characterization}

Whole digestate characteristics are provided in Table 1. TSS was analyzed on each replicate of the derived 17 liquid fractions, according to standard methods [33].

The replicates of the liquid fractions of the control and the 3 lab-scale CES tests characterized by the higher obtained TSS removal were characterized for $\mathrm{pH}$, Total Solids (TS), Conductivity (EC), Total Kjeldahl Nitrogen (TKN), Total Ammonia Nitrogen (TAN), total Phosphorus (P), Chlorides $\left(\mathrm{Cl}^{-}\right)$, and total $\mathrm{HMs}(\mathrm{Cd}, \mathrm{Pb}, \mathrm{Cu}, \mathrm{Hg}, \mathrm{Ni}, \mathrm{Zn}, \mathrm{Cr}$ ) (IRSACNR, 2003). Equivalently, the resulting solid fractions, were tested for TS, Volatile Solids (VS), Total Organic Carbon (TOC), TKN, TAN [34] and HMs (Cd, Pb, Cu, Hg, Ni, Zn, $\mathrm{Cr}$ ) [35-37]. Finally, water extracts were derived from a leaching test performed on the same analyzed solid samples according to a Liquid-to-Solid ratio of 10:1 [38, 39] and characterized for $\mathrm{pH}, \mathrm{EC}, \mathrm{TKN}, \mathrm{TAN}, \mathrm{P}, \mathrm{Cl}^{-}, \mathrm{Al}, \mathrm{HMs}(\mathrm{Cd}$, $\mathrm{Pb}, \mathrm{Cu}, \mathrm{Hg}, \mathrm{Ni}, \mathrm{Zn}, \mathrm{Cr}$ ) [33] and phytotoxicity.

\section{Phytotoxicity Testing}

Seed germination bioassays were performed on prepared eluates according to [40-42]. Each water extract was tested in five different test dilutions with distilled water $(0 \%$ (Control), $5 \%, 15 \%, 50 \%$ and $100 \%$ (vol/vol)) and four replicates for each dilution. For each replicate, $5 \mathrm{~mL}$ of prepared test 
dilution were poured in a Petri dish and covered by filter paper. Then, 10 dicotyledon cress seeds were placed on top of the filter paper and incubated in dark conditions for $72 \mathrm{~h}$ at $25^{\circ} \mathrm{C}$. At the end of incubation period, the shooting seedlings from each replicate were removed from the Petri dish and their length was measured to derive dilution specific Germination Index (GI). Median effect concentrations (EC50) were determined through logistic and linear-logistic regression: the best fitting model was used according to the standard deviation of the distances between fitted and measured data [28].

\section{Performance Calculations and Statistical Aanalysis}

TSS removal (\%) was calculated for each treatment as the complementary to $100 \%$ of the ratio between the TSS values measured in the treated liquid fractions and the control.

The TS removal efficiency $\left(R E_{T S}\right)$ from the replicates of the liquid fractions of the 3 best performing CES treatment was calculated as described by Eq. 1 [43]:

$R E_{T S}=1-T S_{L F} / T S_{I N}$

where $T S_{L F}$ and $T S_{I N}$ are the TS concentrations in the separated liquid fractions and in the whole unseparated digestate, respectively.

Descriptive statistics (mean and standard error) and graphical representation was performed for each investigated parameter and analyzed fractions using Microsoft Excel®16. Also, measured concentration values were processed by ANOVA performing Tukey pairwise comparisons to find significative differences between means $(\mathrm{p}<0.05)$. Normality of datasets were checked by Anderson-Darling test. The software Minitab ${ } 18$ was used to perform inferential statistics.

\section{Results and Discussion}

\section{Influence of CES on the Quality of the Liquid Fraction of Digestate}

\section{TSS Mitigation}

Several CES experiments were conducted to assess TSS removal efficiency of PAC, DEED and PAM products when applied on digestate. During testing, treatments PAC1, PAC2, PACDE1, PACDE2, PACDE3 and PACDE4, led to visible coagulation of solid particles with fast occurrence of a net distinction between solid fraction and clearer supernatant. Conversely, all DEED treatments were characterized by the absence of visible coagulation/flocculation and no clear

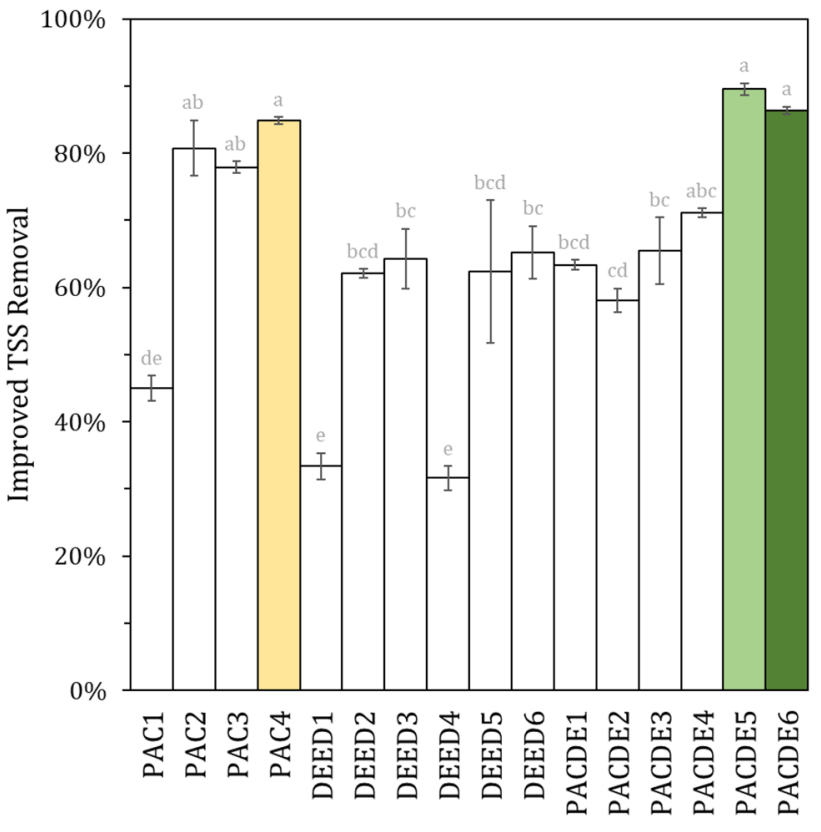

Fig. 1 Average TSS removal improvement (\%) calculated according to the ratio between the TSS values measured in the liquid fractions after each performed CES treatment (see Table 2) and the control. Vertical bars stand for standard errors $(n=3)$. Means that do not share a letter are significantly different $(\mathrm{p}<0.05)$. The colored bars represent the 3 best performing treatments undergone to further chemicalphysical and ecotoxicological characterization

separation of solid and liquid fractions. Instead, the trials PAC3, PAC4, PACDE5 and PACDE6 showed the formation of a thick foam, both during and at the end of the conditioning phase, which did not allow to observe the possible occurrence of coagulation and phase separation. Here, foam formation was noted also in Meixner et al. [11], as due to the volatilization of carbonates alkalinity to carbon dioxide caused by acidic character of spiked $\mathrm{FeCl}_{3}$. However, foam disappeared in the interphase between conditioning test and the following centrifugation step.

Obtained TSS removal values (\%) are depicted in Fig. 1, while detailed data on TSS concentration can be consulted in Table S1 of the Supplementary Material.

Despite the type of involved chemical, each treatment led to a significant increase of TSS removal if compared to the control TSS (i.e., $22.447 \pm 1.150 \mathrm{mg} / \mathrm{L}$ ), ranging from DEED4 with $32 \pm 1 \%$ to PACDE5 with $90 \pm 1 \%$, corresponding to the TSS concentrations of $15,330 \pm 575$ and $2,347 \pm 281 \mathrm{mg} / \mathrm{L}$, respectively (Fig. 1). Measured means and standard deviations of TSS concentration derived from each treatment are included in the Supplementary Material (Table S1).

Reported TSS concentrations in the liquid fractions derived from CES tests with only PAC and PAM dosages are characterized by lower values if compared to all the liquors undergone DEED and PAM application, except for 
PAC1 (Supplementary Material, Table S1). Further, anionic polyacrylamide APAM determined significative higher TSS removal than the same dosage of cationic polyacrylamide CPAM when coupled with lower dosages of PAC (45\% and $81 \%$ for PAC1 and PAC2, respectively) and DEED (34\% and $62 \%$ for DEED1 and DEED2, respectively). This latter trend is inverted with medium applied dosages of DEED (65\% and 32\% for DEED3 and DEED4, respectively). In all the other cases, no significative difference was reported concerning the different efficiency between CPAM and APAM (Fig. 1). These results suggest either that tested DEED and PAM dosages cannot be considered optimal and/or that TSS mitigation was mainly determined by PAC-led coagulation. At the same time, patch flocculation and polymer bridging, which are more related to DEED and PAM actions, could have played a minor role. As suggested by Hjorth et al. [14], this latter aspect could be due to the high conductivity of the treated substrate (i.e., $46.9 \mathrm{mS} / \mathrm{cm}$, Table 1), which could have determined flocculants inefficiencies due to the coiling up of the tested polymers. However, PACDE5 and PACDE6 allowed to obtain the highest TSS removal, showing that a higher dosage of DE and PAM polymers could have enhanced the charge neutralization abilities of Al-based coagulant by adding adsorption (i.e. patch flocculation) and bridging potential $[14,17]$.

To provide a quantitative comparison between the obtained data with published literature, it should be highlighted that available papers do not assess CES efficiency specifically on digestate from biowaste, while on different digested substrates, characterized by different origin and chemical-physical features, (i.e., TS content and type -suspended or dissolved-). Also, related publications studied different chemicals dosages according to experimental design not always reliably comparable. However, the use of PAC + CPAM at a maximum dosage of $24+0.2 \mathrm{~g} / \mathrm{L}$ was reported to decrease up to $23 \%$ of TSS concentration of the separated liquid parts of swine digested slurries after $24 \mathrm{~h}$ of settling (i.e., no centrifugation) [19]. Similarly, several mixtures of aluminum-based coagulants $(10 \mathrm{~g} / \mathrm{kg})$ with polyelectrolytes $(2 \mathrm{~g} / \mathrm{kg})$ and bentonite $(5 \mathrm{~g} / \mathrm{kg})$, spiked before centrifugation, mitigated the TSS down to a range of $33-100 \mathrm{~g} / \mathrm{L}$ in the liquid fraction of digestates from anaerobic co-digestion of sewage sludge, food waste and slaughterhouse waste [20]. On the contrary, to the authors' knowledge, no previous studies investigated the flocculation potential of DEED on digested residues.

As reported by the manufacturer, resulting dosages of PAC and PACDE (Table 2) were approximately one order of magnitude higher than the usual application rates in the field of sludge treatment. Also, the range of tested PAC dosages (i.e., 1.8-3.6 g/L) was almost half than that tested in a similar study involving digested chicken slurry (i.e., 6-24 g/L) [19]. On contrary, tested DEED and PAM dosages are similar to those used in the wastewater sector and, solely for the use of PAM on digestates, to what reported in the scientific literature $[19,30]$. According to 2020 market pricing, the cost of the chemicals used for the 3 best-performing treatments would be around $6 € / \mathrm{m}^{3}$ and $40 € / \mathrm{m}^{3}$ of unseparated digestate, respectively for PAC4 and PACDE5-PACDE6. This cost should be assessed considering the economic burdens that can be avoided by substituting conventional biological membrane pretreatment with CES, such as reduced energetic expenses, smaller plant size and easier operations [13].

\section{Chemical Physical Characterization}

Results of chemical-physical characterization of liquid fractions of the control and the 3 CESs characterized by the higher obtained TSS removal are resumed in Fig. 2. Here, the application of CES led to the variation of the chemical physical characteristics of the liquid fractions of treated digestate. All investigated CES treatments showed lower $\mathrm{pH}$ values (Fig. 2a), as a result of the possible protons release during hydrolysis of PAC molecules [44]. Even if not significantly, lower values of TS could be noted for treated liquid fractions (Fig. 2c), indicating that the CES step could have facilitated the particulate matter removal from the liquid fraction during centrifugation [18]. This is reflected in the values determined for the $R E_{T S}$, which resulted higher than the control in all investigated CES treatments (i.e., 53\%, $58 \%, 59 \%$ and $57 \%$ respectively for control, PAC4, PACDE5 and PACDE6). These values are consistent with separation efficiency values derived from full-scale equipment [43]. In particular, if compared to benchmark values, the calculated $R E_{T S}$ rank all CES treatments as highly efficient separation processes, even if remarkably lower than the average calculated for this category (i.e., RE_TS $=74 \%$ ) [43]. Conversely, control treatment (i.e., centrifugation alone) is positioned exactly at the threshold between high and low efficiency profiles.

Also, increased values of EC (Fig. 2b) can be due to the higher $\mathrm{Cl}^{-}$concentrations characterizing the treated liquors, which are determined by the same PAC dosing (Fig. 2f). Liquid fractions undergone CES are characterized by reduced TKN values and not significantly different TAN concentrations (Fig. 2d). Here, TAN is known to be less prone to flocculate due to their high solubility and limited capacity of adsorption onto polymers. Also, as suggested by higher TAN/TKN ratios in treated liquors (i.e., $86 \%$ in control versus $97 \%, 93 \%$ and $91 \%$, in PAC4, PACDE5 and PACDE6 respectively), CES likely enhanced the flocculation and migration to the solid fractions of the occurring organic N. Conversely, P concentration in liquid phase was reported significantly lower in PAC4 (72\%), PACDE5 and PACDE6 treatments (98\%) (Fig. 2e). As suggested by Luo et al. [19], P removal could have been related more with the absorption of orthophosphates by PAC 

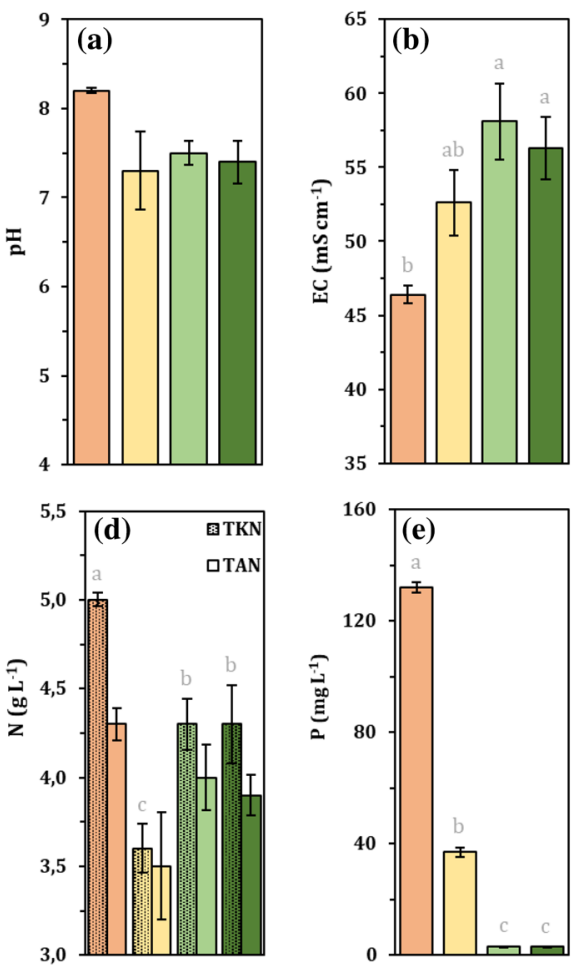
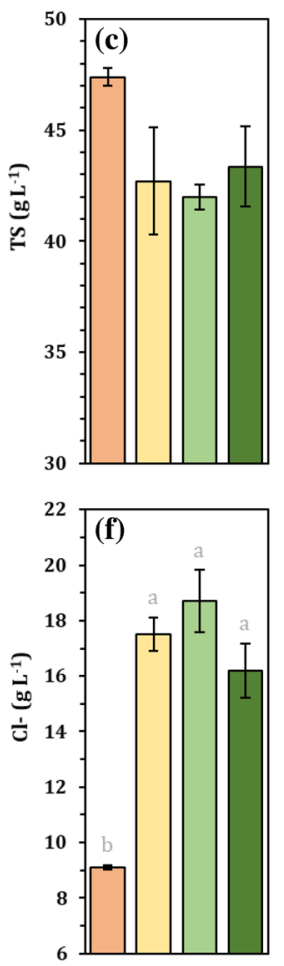

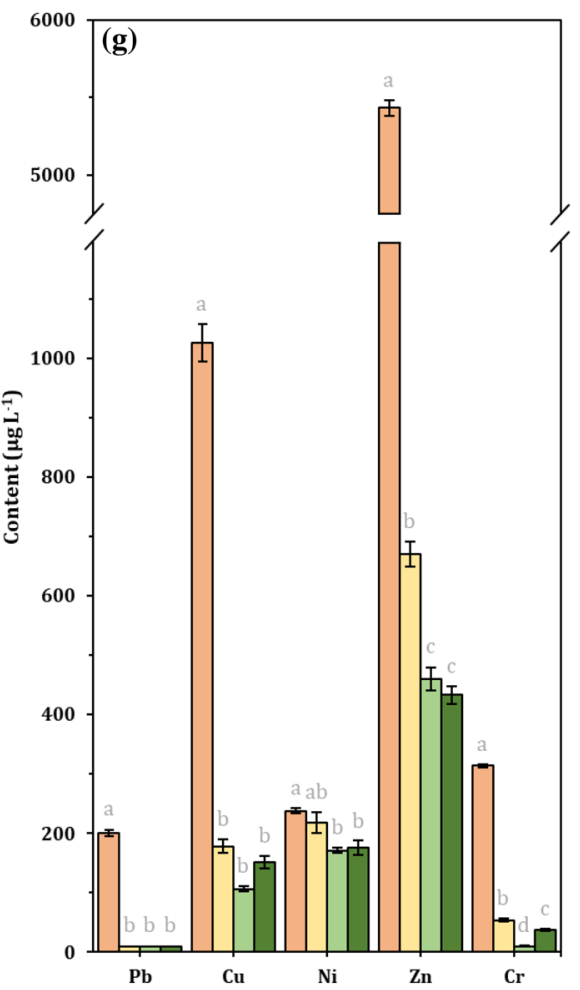

$\square$ Control $\quad \square$ PAC4 $\square$ PACDE5 $\square$ PACDE6

Fig. 2 Chemical-physical characterization of the liquid fractions obtained after centrifugation of control and the 3 CES treatments characterized by lower TSS concentration. Applied treatments are described in Table 2. Vertical bars stand for standard errors $(n=3)$. Means that do not share a letter are significantly different $(\mathrm{p}<0.05)$.

than precipitation with the suspended particles. Furthermore, a lower dissolved $\mathrm{P}$ concentration was reported as a key factor in decreasing inorganic fouling of membranes caused by precipitation of orthophosphates salts [10,13].

Further, the HMs content of treated liquors showed a significant decrease for each assessed CES trials (Fig. 2g). Pb content was found under the LOQ from the treated liquors and on average $86 \%, 90 \%$ and $85 \%$ of $\mathrm{Cu}, \mathrm{Zn}$ and $\mathrm{Cr}$ concentrations were respectively removed during the performed experiments. Also, Ni concentrations were subjected to a decrease after CES performance, but to a lesser extent (i.e., approximately $21 \%$ on average between the applied treatments). The same HMs decreasing behavior in liquid fractions was reported after PAC and PAM application of digested chicken slurry and explained by the binding of HMs molecules through the formation of flocs during CES, which likely were separated with the solid fractions [19].
Absence of letters means that no significant differences were found between treatments. In Fig. 4g, Cr concentrations from all PACDE5 replicates was detected under the Limit of Quantification (LOQ). The full set of analytical results for the liquid fractions is reported in Table S2 in the Supplementary Material

\section{Influence of CES on the Quality of the Solid Fraction of Digestate}

\section{Chemical Physical Characterization}

The characteristics of solid fractions separated after CES performance were investigated to evaluate the reached overall environmental quality for its possible land-spreading in agricultural fields. The results of the analyses conducted on the solid fractions of control and the 3 best performing CES treatments are resumed in Fig. 3.

Applied CES treatments led to higher (not significantly) VS values in solid fractions from PACDE5 and PACDE6 (22\% and $18 \%$ higher than control $-500 \mathrm{~g} \mathrm{~kg}^{-1} \mathrm{TS}$-, respectively), while a slighter increase can be reported for PAC4 (Fig. 3a). 

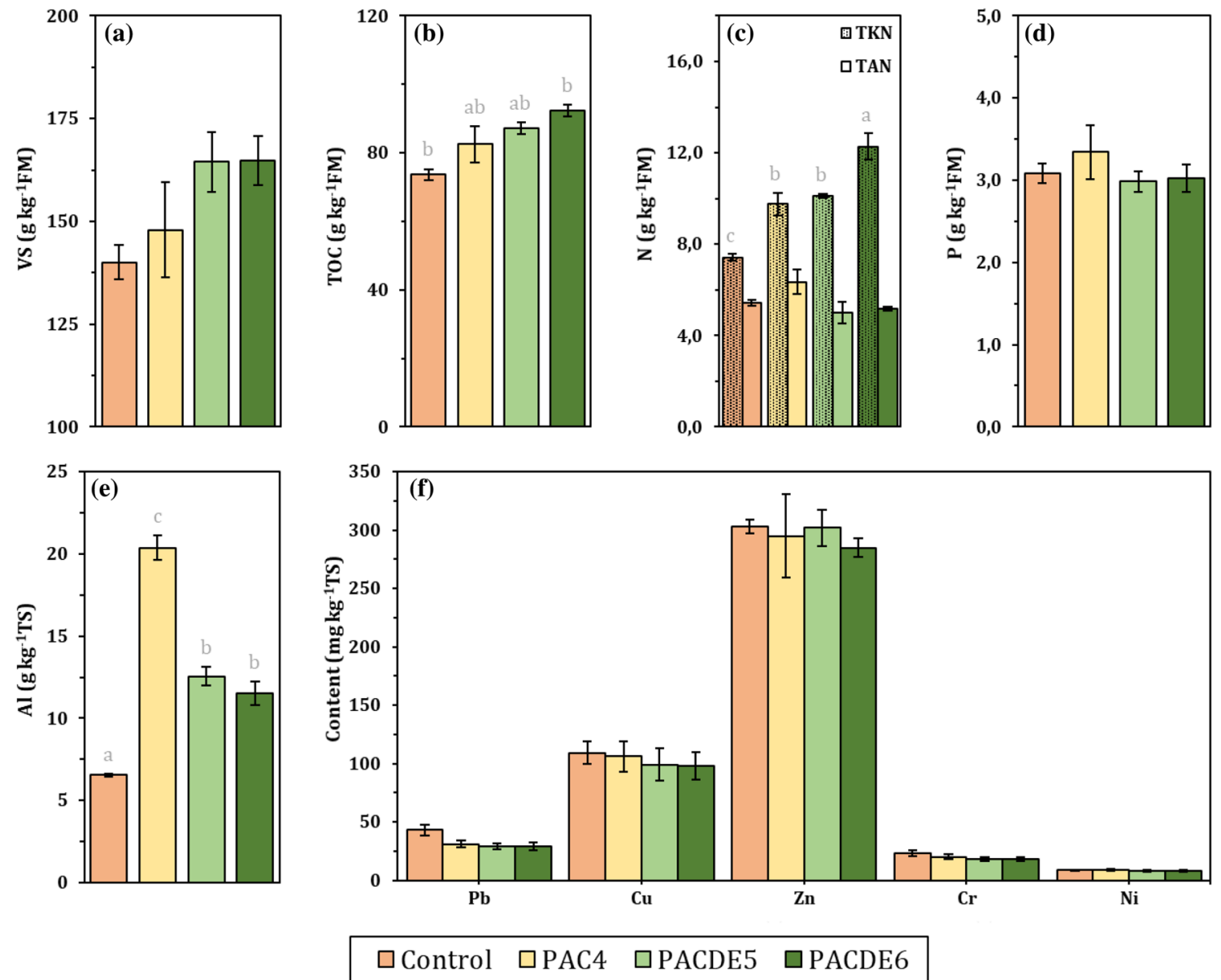

Fig. 3 Chemical-physical characterization of solid fractions separated after centrifugation of control and the 3 best performing CES treatments (see Table 2). Vertical bars stand for standard errors $(n=3)$. All data are expressed on a dry basis (TS), except TS (FM). Means

This trend is reflected in the TOC mean values, resulting $7 \%, 22 \%$ and $25 \%$ higher than the control $\left(263 \mathrm{~g} \mathrm{~kg}^{-1} \mathrm{TS}\right)$ in the biosolids undergone PAC4, PACDE5 and PACDE6 treatments, respectively (Fig. 3b). Also, TKN values highlight a similar figure, showing significantly increased concentrations of $11 \%$ for PAC4 and $46 \%$ and $66 \%$ for PACDE5 (38 $\left.\mathrm{g} \mathrm{kg}^{-1} \mathrm{TS}\right)$ and PACDE6 (44 $\mathrm{g} \mathrm{kg}^{-1}$ TS) (Fig. 3c). Conversely, similar TAN concentrations between the different treatments were detected (Fig. 3c), indicating the organic nature of increased $\mathrm{N}$ content. These trends are likely explained by the increased separation efficiency of fine particles $>0.1 \mu \mathrm{m}$ achieved through CES trials. In fact, while CES is already acknowledged to promote the separation of digestate fine particles with respect to a control treatment (Luo et al., 2018), the majority of organic $\mathrm{C}$ and $\mathrm{N}$ of digestates from biowaste can be found in particle sizes larger than $0.1 \mu \mathrm{m}[22]$. However, the contributions to the increased TKN represented by the possible presence of several nonreported nitro-contaminants, present in the formulation of that do not share a letter are significantly different $(\mathrm{p}<0.05)$. Absence of letters means that no significant differences were found between treatments. The full set of analytical results for the solid fractions is reported in Table S3 in the Supplementary Material

tested conditioning products (i.e., DEED and PAM), should also be better clarified [45].

On contrary, no significative variation is observed for $\mathrm{P}$ content (Fig. 3d) and HMs concentrations (Fig. 3f) in the treated solid fractions if compared with the control treatment, which could be suggested by the characterization of the respective liquid fractions. Here, from a mass balance point of view, most of the potentially separable HMs and $\mathrm{P}$ content may have already been separated by the centrifugation alone, i.e., without the chemicals aid. In other words, the foreseen mass extra-contributes derived from the flocculated particles in the liquid fractions could have played a minor role in determining the final concentrations.

All analyzed fractions resulted compliant with minimum requirements established by the EU regulation for the land spreading of CE-marked "soil improvers", expressed in terms of TS and organic carbon content (Table S3) [27]. However, this is true also for control treatment alone (i.e., simulating centrifugation without any CES). Remarkably, 

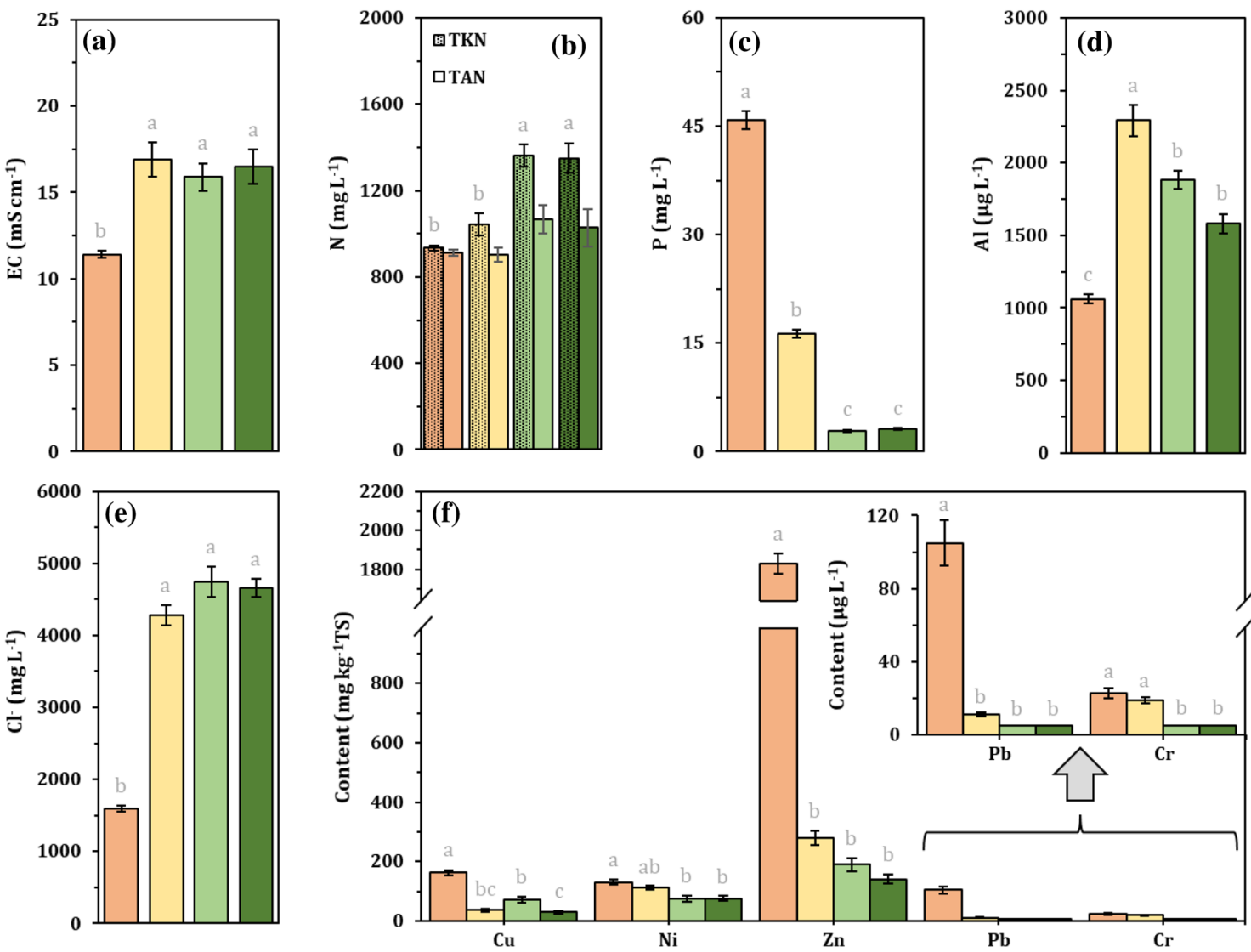

Fig. 4 Chemical-physical characterization of water extracts (L/S ratio $=10$ ) of the solid fractions of the control and the 3 best performing CES treatments. Applied treatments are described in Table 2. Vertical bars stand for standard errors $(\mathrm{n}=3)$. In $\mathrm{f}, \mathrm{Pb}$ and $\mathrm{Cr}$ con-

centrations of PACDE5 and PACDE6 was detected under the LOQ. The full set of analytical results for the investigated water extracts is reported in Table S4 in the Supplementary Material

"soil improver" results the only Product Function Category (PFC) suitable for marketing of the studied solid fractions, given that the measured nutrient contents (i.e., TKN and $\mathrm{P}$ ) do not satisfy the requirements for "organic fertilizers" PFC.

Besides, the treated solid fractions show full compliance with the EU regulation limits imposed for HMs, consistently with the general trend reported for several digestate typologies (Table S3) [8, 26, 27, 46]. Instead, aluminum content increased remarkably in the treated solid fractions as a result of PAC dosages, ranging from about 2-times the control content in PACDE5 $\left(12,552 \mathrm{mg} \mathrm{kg}^{-1} \mathrm{TS}\right)$ and PACDE6 $\left(11,526 \mathrm{mg} \mathrm{kg}^{-1} \mathrm{TS}\right)$ to more than 3-times the control Al concentration in PAC4 treatment $\left(20,376 \mathrm{mg} \mathrm{kg}^{-1} \mathrm{TS}\right)$ (Fig. 3e). Currently, no limits on $\mathrm{Al}$ concentration are set in the mentioned. However, residual bioavailable $\mathrm{Al}$ could show phytotoxic effects, such as decreased plant uptake of essential elements as $\mathrm{P}, \mathrm{K}, \mathrm{Ca}, \mathrm{Mg}, \mathrm{Mo}$ and $\mathrm{B}$, inhibition of root elongation and biomass production and disruption of plant cellular membrane functions, mainly if related with digestate application on acidic soils [8, 19, 47].

\section{Fertilizing Potential, Leachability of HMs and Phytotoxicity of Treated Solid Fractions}

Water extracts derived from the solid fractions of control and the 3 best performing CES trials were characterized to assess possible changes induced by used chemicals on fertilizing characteristics, HMs leachability and phytotoxicity. Figure 4 shows the results from the performed analyses on the water extracts.

Applied CES trials influenced the fertilizing potential of the treated substrates, in terms of nutrient leachability from the tested solid fractions. If compared to the untreated digestate $\left(933 \mathrm{mg} \mathrm{L}^{-1}\right)$, almost $50 \%$ significantly higher TKN concentrations can be noted in the water extracts derived from separated solids undergone PACDE5 and PACDE6, together with a smaller non significative $10 \%$ increase for PAC4 eluate (Fig. 4b). Nevertheless, just 15\% higher (and not significantly) TAN concentrations were measured in eluates from PACDE5 and PACDE6 with respect to the control (913 $\mathrm{mg} \mathrm{L}^{-1}$ ), and no remarkable increase could be reported for PAC4 water extract (Fig. 4b). 
Accordingly, calculated TAN/TKN ratios decrease remarkably in the eluates of test portions treated with PAM and DE (i.e., $87 \%$ in PAC4, 78\% in PACDE5 and 76\% in PACDE6 eluates, against $98 \%$ calculated in the control), suggesting the organic nature of increased $\mathrm{N}$ content. Here, higher TKN could have been determined by the starting composition of the solid fractions showing higher organic $\mathrm{N}$ content (Fig. 3c). Also, it could be linked with the presence of hydrolysis byproducts of aminic groups or other soluble nitro-contaminants present in the dosed products, derived from DE and PAM polymers present in the solid fractions following applied treatments [45]. Here, the potential longterm ecotoxicity and soil-water-plant transfer mechanisms of DEED and PAM by-products must be properly investigated before intended land reuse [45, 48, 49].

Considerably lower P concentrations can be found in treated eluates (Fig. 4c), likely because of the low solubility constant of $\mathrm{Al}-\mathrm{PO}_{4}$ complexes occurring in the solid fractions after CES, as suggested in Luo et al. [19]. Also, the analyzed water extracts showed a remarkably decreased concentration of $\mathrm{Pb}, \mathrm{Cu}, \mathrm{Ni}, \mathrm{Zn}$ and $\mathrm{Cr}$ (Fig. 4f), indicating a general lower water solubility of these elements and potentially reduced environmental risk due to a decreased HMs leaching potential. This was also reported in several solid fractions of sewage sludge coagulated/flocculated with different chemicals because of metallic cations fixation [50, 51]. However, the lower solubility of $\mathrm{Cu}$ and $\mathrm{Zn}$, which can be considered as plant micronutrients, together with the lower $\mathrm{P}$ leachability suggest a decreased fertilizing efficiency of chemically treated solid fractions.

Therefore, the increased EC values recorded in the treated eluates (Fig. 4a), i.e., almost 50\% higher than the control EC $\left(11.4 \mathrm{mS} \mathrm{cm}^{-1}\right)$, were most likely determined by the higher chlorides and soluble aluminum concentrations in the analyzed water extracts. In particular, PAC4 treatment increased leachable $\mathrm{Cl}^{-}$by almost three times $(4,283 \mathrm{mg}$ $\mathrm{L}^{-1}$ ) (Fig. 4e), while leading to double contents of ionic $\mathrm{Al}$ if compared to untreated digestate (Fig. 4d). In particular, PAC4 eluate reached an $\mathrm{Al}$ concentration of $85 \mu \mathrm{mol} \mathrm{L}^{-1}$, which is reported to inhibit root growth in most agriculturally important plants [47, 52, 53]. Nevertheless, it must be pointed out that the cited sources refer to $\mathrm{Al}^{3+}$ solutions derived from acidic soils (with $\mathrm{pH}$ values slightly higher than 4), which is not the case for this study, where the $\mathrm{pH}$ of the eluates resulted slightly alkaline. This aspect could have led to a different speciation of soluble $\mathrm{Al}$ towards less phytotoxic ionic forms (e.g., $\mathrm{Al}(\mathrm{OH})^{2+}$ or $\mathrm{Al}(\mathrm{OH})_{2}{ }^{+}$) [47].

A likely consequence are the lower values of $\mathrm{EC}_{50}$ (\% vol/vol) calculated based on the outcomes from the performed cress seed germination bioassays: $23 \%$, $16 \%, 20 \%$ and $19 \%$ respectively for the control, PAC4, PACDE5 and PACDE6. Remarkably, dose-response curves of treated eluates were not characterized by the typical bio-stimulation behavior characterizing digestates at the lower dilutions [29]. Besides possible aluminum direct phytotoxicity, also high level of TAN and salinity characterizing digested residues, could be the main cause of acute phytotoxicity (i.e., inhibition of seed germination and root elongation) $[28,29,54,55]$. In this context, because of the lower leachable (i.e., bioavailable) concentration of HMs, higher phytotoxicity of treated solid fractions seems to be more correlated with increased salinity of tested eluates, indirectly determined by the soluble Al and $\mathrm{Cl}^{-}$concentrations, resulting from the application of tested products.

\section{Conclusions}

The effects of 16 CES treatments were investigated at labscale when applied on digestate derived from a full-scale AD plant treating biowaste. All applied CES treatments improved TSS reduction of digestate. The 3 best-performing CES treatments were characterized by high dosages of PAC (3.6 g/L), DEED (42 g/L) and PAM (0.32 g/L), allowing to achieve the highest TSS removal rate (up to $90 \pm 1 \%$ with respect to the control) in the liquid fractions separated after centrifugation. These latter showed significantly lower HMs content, which likely migrated to the solid fractions. However, no significative difference in HMs were noted in the conditioned solid fractions., Further, treated solids resulted compliant with the EU requirements for their agricultural reuse as "organic soil amendment", established in terms of minimum TS and organic carbon and concentration limits for HMs. However, analysis of treated eluates highlighted decreased $\mathrm{P}$ and useful HMs leachability, higher chlorides and Al concentrations together with an increased phytotoxicity if compared with untreated digestate.

In summary, this study could act as a first attempt to define PAC, DEED and PAM dosages to efficiently perform CES as an alternative to other membrane pre-treatments (e.g., biological) for the complete purification of digestate liquid fraction. However, the achieved quality of the resulting solid fractions suggests further research regarding possible adverse environmental effects derived by their agricultural reuse both in the short term (e.g., lab-scale test for early emergence and growth of different plant species -e.g., lettuce, tomato, etc.) and in the long term (e.g., field or greenhouse investigations of plant-uptake of $\mathrm{Al}$ and nitrous contaminants). Alternatively, treated biosolids could be disposed or sent to further treatments prior to thermal valorization.

Supplementary Information The online version contains supplementary material available at https://doi.org/10.1007/s12649-021-01591-y. 
Funding Open access funding provided by Università degli Studi di Padova within the CRUI-CARE Agreement.

Open Access This article is licensed under a Creative Commons Attribution 4.0 International License, which permits use, sharing, adaptation, distribution and reproduction in any medium or format, as long as you give appropriate credit to the original author(s) and the source, provide a link to the Creative Commons licence, and indicate if changes were made. The images or other third party material in this article are included in the article's Creative Commons licence, unless indicated otherwise in a credit line to the material. If material is not included in the article's Creative Commons licence and your intended use is not permitted by statutory regulation or exceeds the permitted use, you will need to obtain permission directly from the copyright holder. To view a copy of this licence, visit http://creativecommons.org/licenses/by/4.0/.

\section{References}

1. Corden, C., Bougas, K., Cunningham, E., Tyrer, D., Kreißig, J., Zetti, E., Gamero, E., Wildey, R., Crookes, M.: Digestate and compost as fertilisers: risk assessment and risk management options. Wood Environment \& Infrastructure Solutions UK Ltd, Cheshire (2019)

2. Al Seadi, T., Lukehurst, C.: Quality management of digestate from biogas plants used as fertiliser. IEA Bioenergy Task 37, 40 (2012)

3. Dahlin, J., Herbes, C., Nelles, M.: Biogas digestate marketing: qualitative insights into the supply side. Resources Conserv. Recycl. 104, 152-161 (2015). https://doi.org/10.1016/j.resconrec. 2015.08.013

4. Sawatdeenarunat, C., Nguyen, D., Surendra, K.C., Shrestha, S., Rajendran, K., Oechsner, H., Xie, L., Khanal, S.K.: Anaerobic biorefinery: current status, challenges, and opportunities. Bioresour. Technol. 215, 304-313 (2016). https://doi.org/10.1016/j. biortech.2016.03.074

5. Alibardi, L., Astrup, T.F., Asunis, F., Clarke, W.P., De Gioannis, G., Dessì, P., Lens, P.N.L., Lavagnolo, M.C., Lombardi, L., Muntoni, A., Pivato, A., Polettini, A., Pomi, R., Rossi, A., Spagni, A., Spiga, D.: Organic waste biorefineries: looking towards implementation. Waste Manag. 114, 274-286 (2020). https://doi.org/ 10.1016/j.wasman.2020.07.010

6. Fuchs, W., Drosg, B.: Assessment of the state of the art of technologies for the processing of digestate residue from anaerobic digesters. Water Sci. Technol. 67, 1984-1993 (2013). https://doi. org/10.2166/wst.2013.075

7. Peng, W., Pivato, A.: Sustainable management of digestate from the organic fraction of municipal solid waste and food waste under the concepts of back to earth alternatives and circular economy. Waste Biomass Valoriz. (2017). https://doi.org/10.1007/ s12649-017-0071-2

8. Vaneeckhaute, C., Darveau, O., Meers, E.: Fate of micronutrients and heavy metals in digestate processing using vibrating reversed osmosis as resource recovery technology. Sep. Purif. Technol. 223, 81-87 (2019). https://doi.org/10.1016/j.seppur.2019.04.055

9. Waeger, F., Delhaye, T., Fuchs, W.: The use of ceramic microfiltration and ultrafiltration membranes for particle removal from anaerobic digester effluents. Sep. Purif. Technol. 73, 271-278 (2010). https://doi.org/10.1016/j.seppur.2010.04.013

10. Guo, W., Ngo, H.H., Li, J.: A mini-review on membrane fouling. Bioresour. Technol. 122, 27-34 (2012). https://doi.org/10.1016/j. biortech.2012.04.089

11. Meixner, K., Fuchs, W., Valkova, T., Svardal, K., Loderer, C., Neureiter, M., Bochmann, G., Drosg, B.: Effect of precipitating agents on centrifugation and ultrafiltration performance of thin stillage digestate. Sep. Purif. Technol. 145, 154-160 (2015). https://doi.org/10.1016/j.seppur.2015.03.003

12. Shi, L., Xie, S., Hu, Z., Wu, G., Morrison, L., Croot, P., Hu, H.: Nutrient recovery from pig manure digestate using electrodialysis reversal: membrane fouling and feasibility of long-term operation. J. Memb. Sci. 573, 560-569 (2019). https://doi.org/10.1016/j. memsci.2018.12.037

13. Even-Ezra, I., Beliavski, M., Tarre, S., Dosoretz, C., Green, M.: Chemical versus biological pretreatment for membrane filtration of domestic wastewater. Desalination 272, 85-89 (2011). https:// doi.org/10.1016/j.desal.2011.01.015

14. Hjorth, M., Christensen, K.V., Christensen, M.L., Sommer, S.G.: Soli-liquid separation of animal slurry in therory and practice. A review. Agron. Sustain. Dev. 30, 153-180 (2010). https://doi.org/ 10.1051/agro/2009010

15. Metcalf, E.: Wastewater Engineering: Treatment and Resource Recovery. McGraw-Hill, New York (2013)

16. Hjorth, M., Jørgensen, B.U.: Polymer flocculation mechanism in animal slurry established by charge neutralization. Water Res. 46, 1045-1051 (2012). https://doi.org/10.1016/j.watres.2011.11.078

17. Bu, F., Gao, B., Li, R., Sun, S., Yue, Q.: Impacts of epichlorohydrin-dimethylamine on coagulation performance and membrane fouling in coagulation/ultrafiltration combined process with different Al-based coagulants. Chemosphere 159, 228-234 (2016). https://doi.org/10.1016/j.chemosphere.2016.06.001

18. Camilleri-Rumbau, M.S., Popovic, O., Briceño, K., Errico, M., Søtoft, L.F., Christensen, K.V., Norddahl, B.: Ultrafiltration of separated digestate by tubular membranes: influence of feed pretreatment on hydraulic performance and heavy metals removal. J. Environ. Manage. 250, 109404 (2019). https://doi.org/10.1016/j. jenvman.2019.109404

19. Luo, H., Lyu, T., Muhmood, A., Xue, Y., Wu, H., Meers, E., Dong, R., Wu, S.: Effect of flocculation pre-treatment on membrane nutrient recovery of digested chicken slurry: mitigating suspended solids and retaining nutrients. Chem. Eng. J. 352, 855-862 (2018). https://doi.org/10.1016/j.cej.2018.07.097

20. Borowski, S., Boniecki, P., Kubacki, P., Czyżowska, A.: Food waste co-digestion with slaughterhouse waste and sewage sludge: digestate conditioning and supernatant quality. Waste Manag. 74, 158-167 (2018). https://doi.org/10.1016/j.wasman.2017.12.010

21. Akhiar, A., Guilayn, F., Torrijos, M., Battimelli, A., Shamsuddin, A.H., Carrère, H.: Correlations between the composition of liquid fraction of full-scale digestates and process conditions. Energies (2021). https://doi.org/10.3390/en14040971

22. Lü, F., Zhou, Q., Wu, D., Wang, T., Shao, L., He, P.: Dewaterability of anaerobic digestate from food waste: relationship with extracellular polymeric substances. Chem. Eng. J. 262, 932-938 (2015). https://doi.org/10.1016/j.cej.2014.10.051

23. Lukehurst, C., Frost, P., Al Seadi, T.: Utilisation of digestate from biogas plants as biofertiliser. IEA Bioenergy, pp. 1-36 (2010)

24. Tambone, F., Genevini, P., D'Imporzano, G., Adani, F.: Assessing amendment properties of digestate by studying the organic matter composition and the degree of biological stability during the anaerobic digestion of the organic fraction of MSW. Bioresour. Technol. 100, 3140-3142 (2009). https://doi.org/10.1016/j.biort ech.2009.02.012

25. Tambone, F., Scaglia, B., D'Imporzano, G., Schievano, A., Orzi, V., Salati, S., Adani, F.: Assessing amendment and fertilizing properties of digestates from anaerobic digestion through a comparative study with digested sludge and compost. Chemosphere 81, 577-583 (2010). https://doi.org/10.1016/j.chemosphere.2010. 08.034

26. Tambone, F., Orzi, V., D'Imporzano, G., Adani, F.: Solid and liquid fractionation of digestate: mass balance, chemical characterization, and agronomic and environmental value. Bioresour. 
Technol. 243, 1251-1256 (2017). https://doi.org/10.1016/j.biort ech.2017.07.130

27. European Parliament, European Council: Regulation 2019/1009/ EU of the European Parliament and of the Council of 5 June 2019 laying down rules on the making available on the market of EU fertilising products and amending Regulations (EC) No 1069/2009 and (EC) No 1107/2009 and repealing Regulati (2019)

28. Bona, D., Beggio, G., Weil, T., Scholz, M., Bertolini, S., Grandi, L., Baratieri, M., Schievano, A., Silvestri, S., Pivato, A.: Effects of woody biochar on dry thermophilic anaerobic digestion of organic fraction of municipal solid waste. J. Environ. Manage. (2020). https://doi.org/10.1016/j.jenvman.2020.110633

29. Pivato, A., Vanin, S., Raga, R., Lavagnolo, M.C., Barausse, A., Rieple, A., Laurent, A., Cossu, R.: Use of digestate from a decentralized on-farm biogas plant as fertilizer in soils: an ecotoxicological study for future indicators in risk and life cycle assessment. Waste Manag. 49, 378-389 (2016). https://doi.org/10.1016/j.wasman.2015.12.009

30. Chuda, A., Ziemiński, K.: Digestate mechanical separation in industrial conditions: efficiency profiles and fertilising potential. Waste Manag. 128, 167-178 (2021). https://doi.org/10.1016/j. wasman.2021.04.049

31. Popovic, O., Hjorth, M., Stoumann Jensen, L.: Phosphorus, copper and zinc in solid and liquid fractions from full-scale and laboratory-separated pig slurry. Environ. Technol. (United Kingdom) 33, 2119-2131 (2012). https://doi.org/10.1080/09593330.2012. 660649

32. Möller, H.B., Jensen, H.S., Tobiasen, L., Hansen, M.N.: Heavy metal and phosphorus content of fractions from manure treatment and incineration. Environ. Technol. 28, 1403-1418 (2007). https:// doi.org/10.1080/09593332808618900

33. IRSA-CNR (Italian Water Research Institute), APAT (Italian Environmental Agency): Metodi analitici per le acque (2003)

34. IRSA-CNR (Italian Water Research Institute): Quaderno n. 64 METODI ANALITICI PER I FANGHI (1998)

35. USEPA: Method 7471B (SW-846): Mercury in solid or semisolid wastes. Revision 2 (1994)

36. USEPA: Method 3050B: Acid Digestion of sediments, sludges and soils. Revision 2 (1996)

37. USEPA: Method 6010D (SW-846): Inductively coupled plasmaatomic emission spectrometry. Revision 4 (2014)

38. CEN: EN 12457-2 - Leaching - Compliance test for leaching of granular waste materials and sludges. Part 2: One stage batch test at a liquid to solid ratio of $10 \mathrm{l} / \mathrm{kg}$ for materials with particles size below $4 \mathrm{~mm}$ (with or without size reduction) (2004)

39. CEN: EN ISO 14735 - Preparation of waste samples for ecotoxicity tests (2005)

40. APAT (Italian Environmental Agency): Guida tecnica su metodi di analisi per il suolo e i siti contaminati - Utilizzo di indicatori biologici ed ecotossicologici (2004)

41. ISO: ISO 17126 - Soil quality-Determination of the effects of pollutants on soil flora. Screening test for emergence of lettuce seedlings (Lactuca sativa L.). International Organization for Standardization. 3 (2005)

42. USEPA: Ecological Effects Test Guidelines OPPTS (850.4200): Seed Germination/Root Elongation Toxicity. (1996)

43. Guilayn, F., Crest, M., Rouez, M., Patureau, D., Jimenez, J.: Digestate mechanical separation: efficiency profiles based on anaerobic digestion feedstock and equipment choice. Bioresour.
Technol. 274, 180-189 (2018). https://doi.org/10.1016/j.biortech. 2018.11.090

44. Davis, C.C., Edwards, M.: Coagulation with hydrolyzing metal salts: mechanisms and water quality impacts. Crit. Rev. Environ. Sci. Technol. 44, 303-347 (2014). https://doi.org/10.1080/10643 389.2012.718947

45. Letterman, R.D., Pero, R.W.: Contaminants in polyelectrolytes used in water treatment. J. / Am. Water Work. Assoc. 82, 87-97 (1990). https://doi.org/10.1002/j.1551-8833.1990.tb07056.x

46. Kupper, T., Bürge, D., Bachmann, H.J., Gsewell, S., Mayer, J.: Heavy metals in source-separated compost and digestates. Waste Manag. 34, 867-874 (2014). https://doi.org/10.1016/j.wasman. 2014.02.007

47. Shetty, R., Vidya, C.S.N., Prakash, N.B., Lux, A., Vaculík, M.: Aluminum toxicity in plants and its possible mitigation in acid soils by biochar: a review. Sci. Total Environ. (2020). https://doi. org/10.1016/j.scitotenv.2020.142744

48. Bamba, D., Coulibaly, M., Robert, D.: Nitrogen-containing organic compounds: origins, toxicity and conditions of their photocatalytic mineralization over $\mathrm{TiO} 2$. Sci. Total Environ. 580, 1489-1504 (2017). https://doi.org/10.1016/j.scitotenv.2016.12. 130

49. Bhat, A.P., Gogate, P.R.: Degradation of nitrogen-containing hazardous compounds using advanced oxidation processes: a review on aliphatic and aromatic amines, dyes, and pesticides. J. Hazard. Mater. 403, 123657 (2021). https://doi.org/10.1016/j.jhazm at.2020.123657

50. Liang, J., Zhang, L., Ye, M., Guan, Z., Huang, J., Liu, J., Li, L., Huang, S., Sun, S.: Evaluation of the dewaterability, heavy metal toxicity and phytotoxicity of sewage sludge in different advanced oxidation processes. J. Clean. Prod. 265, 121839 (2020). https:// doi.org/10.1016/j.jclepro.2020.121839

51. Xiong, Q., Zhou, M., Liu, M., Jiang, S., Hou, H.: The transformation behaviors of heavy metals and dewaterability of sewage sludge during the dual conditioning with $\mathrm{Fe} 2+$-sodium persulfate oxidation and rice husk. Chemosphere 208, 93-100 (2018). https://doi.org/10.1016/j.chemosphere.2018.05.162

52. Silva, I.R., Smyth, T.J., Raper, C.D., Carter, T.E., Rufty, T.W.: Differential aluminum tolerance in soybean: an evaluation of the role of organic acids. Physiol. Plant. 112, 200-210 (2001). https:// doi.org/10.1034/j.1399-3054.2001.1120208.x

53. Samac, D.A., Tesfaye, M.: Plant improvement for tolerance to aluminum in acid soils: a review. Plant Cell. Tissue Organ Cult. 75, 189-207 (2003). https://doi.org/10.1023/A:1025843829545

54. Teglia, C., Tremier, A., Martel, J.L.: Characterization of solid digestates: Part 1, review of existing indicators to assess solid digestates agricultural use. Waste Biomass Valoriz. 2, 43-58 (2011). https://doi.org/10.1007/s12649-010-9051-5

55. Tigini, V., Franchino, M., Bona, F., Varese, G.C.: Is digestate safe? A study on its ecotoxicity and environmental risk on a pig manure. Sci. Total Environ. 551-552, 127-132 (2016). https://doi.org/10. 1016/j.scitotenv.2016.02.004

Publisher's Note Springer Nature remains neutral with regard to jurisdictional claims in published maps and institutional affiliations. 


\section{Authors and Affiliations}

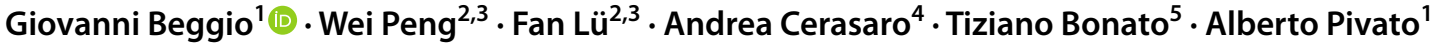

$\triangle$ Giovanni Beggio

giovanni.beggio@unipd.it

1 Department of Civil, Environmental and Architectural Engineering, University of Padova, Via Marzolo 9, 35131 Padova, Italy

2 State Key Laboratory of Pollution Control \& Resource Reuse, Tongji University, Shanghai 200092, People's Republic of China
3 Shanghai Institute of Pollution Control and Ecological Security, Shanghai 200092, People's Republic of China

4 Vice S.R.L, Villorba Di Treviso, via Fratelli Cervi 25, 31020 Villorba, TV, Italy

5 Società Estense Servizi Ambientali (S.E.S.A. S.P.A.), Via Comuna 5/B, 35042 Este, PD, Italy 